\title{
Reducing Energy Use and Carbon Emissions: A Critical Assessment of Small-Group Interventions
}

\author{
Jill Fisher ${ }^{1, *}$ and Katherine Irvine ${ }^{2}$ \\ 1 Institute of Energy and Sustainable Development, De Montfort University, Queens Building, The Gateway, \\ Leicester LE1 9BH, UK \\ 2 Social, Economic and Geographical Sciences, James Hutton Institute, Craigiebuckler, Aberdeen AB15 8QH, \\ UK; katherine.irvine@hutton.ac.uk \\ * Correspondence: j.fisher@dmu.ac.uk; Tel.: +44-116-207-8711
}

Academic Editor: Enrico Sciubba

Received: 14 December 2015; Accepted: 1 March 2016; Published: 8 March 2016

\begin{abstract}
Motivating individuals to decrease the environmental impact of their lifestyles could play an important role in reducing energy use and meeting carbon reduction commitments in developed countries. Few approaches which encourage voluntary changes in behaviour result in substantial reductions in energy use, however, particularly over the longer term. An exception to this general trend is small-group interventions which use group participation and which target collections of behaviours including energy use. Through a critical examination of published data this paper considers the energy and carbon emission reductions achieved by such initiatives, the durability of those reductions, and the common elements which may contribute to their success. Participants in small-group interventions reduced their energy use and carbon emissions by approximately $20 \%$ within a year. There is also some evidence that these reductions were lasting and that participants continued to make changes to their lifestyles after the end of the intervention. The reasonable person model (RPM) is proposed as a useful framework for understanding the success of these small-group interventions. Examination of small-group interventions suggests that they provide settings which are supportive of informational needs, and that this may be important to their success in promoting substantial and durable decreases in energy use.
\end{abstract}

Keywords: energy use; behaviour change; small-group discussion; reasonable person model (RPM); interventions; evaluation; carbon emission reduction

\section{Introduction}

Motivating individuals to reduce the environmental impact of their lifestyles is an important component of reducing energy use and meeting carbon reduction commitments in developed countries. The UK Energy Research Centre estimated that changes in individual and household behaviour in the United Kingdom (UK) could contribute a 30\% cut in emissions on 1990 levels [1], and Dietz et al. [2] suggested that simple behaviour changes could contribute a $20 \%$ reduction in direct household carbon emissions in the United States (US). Despite such potential, pro-environmental behaviour change programmes have yet to be successful in delivering meaningful reductions in energy use or carbon emissions, particularly over the longer term [3-5]. For example, a review of 38 interventions targeting household energy use by Abrahamse et al. [6] found either no reduction or a reduction of less than $5 \%$ in energy use across the majority of the interventions. This scale of reduction is woefully inadequate if behaviour change in the domestic sector is to contribute its share to meeting carbon reduction targets.

Permanence of change was also an issue raised about the interventions examined in Abrahamse et al.'s review [6]. The long term effects of the interventions-reductions still in effect after two or more months-were considered in 13 of the 38 studies; only five studies reported that 
reductions were maintained [6]. Haq et al. [4] identified a similar problem with changing transport behaviour in York, a city in the north of England. Although they document statistically significant changes 6 months after the intervention, there was a return to original behaviour patterns after 12 months.

A further concern is that many programmes designed to promote energy reduction and other pro-environmental behaviour focus on a single specific behaviour or attitude with little attempt to influence related behaviours or overall lifestyle [1]. Even when these interventions have successfully promoted substantial change in the targeted behaviour there is little evidence of impact on other pro-environmental behaviours [7]. Nevertheless focusing on specific behaviours in isolation continues to be the standard approach to promoting energy reduction and other pro-environmental behaviour $[8,9]$. A concentration on single behaviours may in fact be inappropriate given evidence which suggests that groups of pro-environmental behaviours co-vary [10-12]. Indeed there is some evidence that concentrating on a single behaviour could be counter-productive as it can lead individuals to focus their pro-environmental intentions on that particular behaviour rather than on behaviours that may have greater environmental impact $[13,14]$. A further difficulty with concentrating on a single behaviour is the risk that individuals will engage in compensatory behaviour; excusing environmentally damaging behaviour in one domain by practicing pro-environmental behaviour in another [15].

If voluntary increases in pro-environmental behaviour are to make a meaningful contribution to reducing energy use and carbon emissions it is crucial that programmes promoting pro-environmental behaviour deliver both substantial and durable change. It is also important that they target an assortment of pro-environmental behaviours. Given the limited success of behaviour change initiatives in reducing energy use or promoting increases in other pro-environmental behaviour, there is an urgent need to understand how such behaviour can be encouraged. Stern [13] and others $[12,16,17]$ have pointed out that pro-environmental behaviour is multidimensional, with different determinants for different behaviours. The difficulty with commonly used behaviour change models such as the Theory of Planned Behaviour [18] and the Value-Belief-Norm Theory [13] is that they are not generally useful for predicting multiple behaviours [5]. Attempting to model each behaviour change within a group of interrelated behaviours could be an unwieldy task, and might well fail to take into account interaction between the behaviours. A coherent theoretical framework which facilitated the design and evaluation of interventions that targeted multiple behaviours would further our understanding of how to encourage pro-environmental behaviour.

There is a recently developed framework, the reasonable person model (RPM) [19,20], which may be conceptually suited to understanding how groups of behaviours might be influenced. Rather than seeking to identify specific antecedents to particular behaviours, the RPM calls for an approach which concentrates on the environments, broadly construed, i.e., physical, social and cognitive, within which people operate. Central to the RPM is the idea that humans have a basic need to interact with and make sense of the world around them. Specifically, the RPM links human behaviour with the ability of the environment to support human informational needs by proposing that environments which are supportive of such needs foster reasonable behaviour in people. We suggest that "reasonable" behaviour for people who are concerned about the environmental impact of their daily lives might be reflected by pro-environmental behaviour (e.g., turning the thermostat down, installing energy efficiency measures). The potential for such behaviour to increase might then be a function of the degree to which interventions provide environments that are supportive. The RPM defines a supportive environment as one which allows people to build and extend their mental models, to exercise and develop competence, and to participate and feel needed.

This paper specifically examines whether the RPM might be helpful for understanding successful behaviour change interventions. We do this by identifying interventions that do effectively foster substantial and durable changes in behaviour. We then examine the details of these interventions through the lens of the RPM framework to consider possible mechanisms associated with that 
effectiveness. By identifying such mechanisms we hope to provide insight into how other types of interventions might be made more effective in promoting the behaviour change needed to deliver significant reductions in carbon emissions.

\section{Effective Interventions}

Abrahamse et al.'s [6] reviewed highlights that some intervention types are more successful than others. Of the interventions reviewed, the only one which showed a substantial and lasting reduction in energy use was the EcoTeams programme in the Netherlands. EcoTeams is one of an increasing number of programmes which use a small-group approach and target collections of behaviours or lifestyles [21-27]. These programmes bring together small groups of people to jointly consider a variety of behaviours and attitudes in a study group format similar to those used in healthcare contexts $[28,29]$. Participants in these small-group interventions are reported to achieve substantial and lasting reductions in energy use and carbon emissions.

To explore further the effectiveness of small-group interventions in increasing pro-environmental behaviour and decreasing energy use we adopted De Young's [30] evaluative dimensions to assess the success of small-group interventions in changing behaviour. These dimensions provide a useful set of standard criteria for assessing behaviour change interventions.

To identify small-group interventions for evaluation, electronic searches for literature about small-group interventions targeting pro-environmental behaviour were conducted using the following keywords separately and in combination: "pro-environmental behaviour", "intervention", "group based", "carbon reduction", and "behaviour change". Databases searched included PSYCHInfo, Scopus, and Science Direct. Google Scholar was also used to help identify literature not available in peer-reviewed journals. Reference lists of relevant papers were searched manually for additional material and citation searches were also conducted for literature identified through keyword searches.

\subsection{Selection of Studies}

We selected studies for examination based on three criteria. First, the programme considered in the study needed to target multiple behaviours. Second, it needed to use a small-group approach with regular face-to-face contact between participants. Lastly, the study needed to include objective data based on actual energy use by participants. The inclusion of objective information as a selection criterion was important to facilitate our evaluation of the effectiveness of the programmes based on measured changes in energy use and carbon emissions.

We identified only four small-group interventions targeting pro-environmental behaviour which contained objective information on actual energy use and/or carbon emissions. Due to the paucity of peer-reviewed literature about the effectiveness of these interventions, we included information from both peer-reviewed papers and project reports in our analysis-unfortunately a comparison to the wider population in terms of changes in pro-environmental behavior was included in only one study.

\subsection{Description of Small-Group Interventions}

The four small-group interventions identified in the literature search had several features in common. The group size ranged from six to ten individuals. Meetings were held regularly, participants had access to reliable information through written material and/or access to a trained "expert" and were provided an opportunity to explore the information as a group. The interventions addressed collections of behaviours with the stated purpose of reducing the environmental impact of the participants' lifestyles. Groups were usually drawn from a neighbourhood, a workplace or a community of interest such as a faith group or a voluntary group.

\subsubsection{EcoTeams Netherlands}

The longest established and largest of the programmes considered here is EcoTeams which is run by Global Action Plan (GAP) both in the UK [26,31], and internationally [27,32]. EcoTeams 
groups in the Netherlands met once a month for 8 months with a specified monthly topic [27]. Each participant received an information pack and workbook, and had access either to a trained facilitator or to someone at a support centre. Exploration, discussion, and sharing of information were encouraged. To monitor reductions, participants took gas and electric meter readings; additional monitoring of behaviour change was done through weighing of household waste. These data were recorded in an individual logbook which participants submitted to GAP who then provided feedback about any changes in energy use [32]. Changes in electricity and gas use were adjusted for external temperature to allow comparison across time. The Dutch EcoTeams programme has been extensively assessed in a longitudinal study of 153 households through questionnaires and measurement of energy, waste and water use [27,32]. Comparative analyses were also conducted between programme participants and the wider Dutch population [27].

\subsubsection{EcoTeams UK}

UK EcoTeams were similar in structure to the Dutch EcoTeams. The monthly meetings were held over 5 months with a specific topic for each meeting. Information packs and workbooks were provided to each participant and meetings were facilitated by trained facilitators who had access to further information and advice from GAP [31]. As with the Dutch EcoTeams, participants were encouraged to explore, discuss and share information. Changes in behaviour were monitored by recording electricity and gas use through meter readings, and weighing household waste; this information was submitted to GAP UK. The feedback provided about any reductions was personalized rather than focused at the group level. Energy use was adjusted for external temperature to allow comparison across time. The UK EcoTeams programme has been assessed both by GAP UK $[31,33]$ through questionnaires and measurement of energy, waste and water use, and by Nye and Burgess [26] in a government-commissioned evaluation focusing on energy use and waste reduction. By 2008 a total of 3602 UK households had participated in EcoTeams and household consumption data were available for 1096 households [31].

\subsubsection{Carbon Reduction/Rationing Action Groups}

The third small-group intervention considered here is the Carbon Reduction/Rationing Action Group (CRAG) [23,24,34]. The CRAG movement is a loosely knit community of people who meet together in groups to identify ways to reduce their carbon emissions. Unlike EcoTeams, there is no set structure for how CRAGs function, although the CRAG website [34] provided suggestions. Individual CRAGs chose how often to meet (often monthly) and the topics to be discussed [23]. CRAGs have no trained facilitators, but groups were supported by information on the CRAG web site. Members of CRAGs agreed amongst themselves how to record changes in energy use and emissions, recorded their own electricity and gas meter readings as well as vehicle odometer readings, and shared information at regular meetings [23,24]. Howell [23,24] analysed information about energy use and carbon reductions posted to the CRAG web site from five different CRAG groups in the UK and documented the carbon reductions reported by the 50 participants.

\subsubsection{Green Streets}

A slightly different small-group intervention was conducted by British Gas in the UK from 2008 to 2009 as part of its Green Streets programme [25]. In this programme eight households were recruited in each of eight streets to form neighbourhood teams with the intention of reducing the emissions of all the households in the team. The team that made the largest reductions won a cash prize. Green Streets households had access to a dedicated energy advisor who provided information and expert advice, and answered queries [25]. The teams met regularly to discuss and share information over the 12 month period. British Gas also provided each group with $£ 30,000$ of funding to make improvements to their homes, including a mandatory element of renewable energy generation. Green Streets participants were provided with feedback through both real-time hand-held meters, which continuously displayed 
electricity consumption, and monitoring of energy consumption through monthly electricity and gas meter readings.

\subsection{Evaluating Effectiveness}

De Young [30] proposed five dimensions for assessing the strengths and weaknesses of different intervention types for fostering behaviour change. These dimensions include: reliability, speed of change, durability, generality, and particularism. Here we consider the performance of the four programmes for each of these dimensions.

\subsubsection{Reliability}

The first criterion is reliability which considers how successful a technique is at instigating behaviour change [30]. Published evaluations of the four small-group interventions have found average reductions in energy use and carbon emissions of approximately $20 \%$, ranging from $17 \%$ to $27 \%$ [23-27]. Table 1 summarises the reductions achieved by each of these programmes. It should be noted that Lockwood and Platt [25] attributed approximately $50 \%$ of the reductions achieved by Green Streets participants to behaviour change alone, with the other $50 \%$ being attributable to installed measures.

Table 1. Previously published reductions in energy use and carbon emissions for small-group interventions. CRAG: carbon reduction/rationing action group.

\begin{tabular}{ccccc}
\hline Programme & $\begin{array}{c}\text { Number of } \\
\text { Participants }\end{array}$ & Percent Reduction in Energy Use & $\begin{array}{c}\text { Percent Carbon } \\
\text { Reduction }\end{array}$ & Data Source \\
\hline Netherlands & 153 & Electricity: 7\%; gas: 23\% & Unreported & $\begin{array}{c}\text { Meter readings } \\
\text { EcoTeams [27] }\end{array}$ \\
UK EcoTeams [26] & 1096 & Electricity: 7\%; gas: $21 \%$ & $17 \%$ & reported by participants \\
CRAGs [23] & 50 & Unreported & $27 \%$ & Meter readings \\
\hline Green Streets [25] & 64 & Energy (electricity and gas): 25\% & $23 \%$ & collected by British Gas \\
\hline
\end{tabular}

\subsubsection{Speed of Change}

All four interventions achieved substantial reductions in energy use and/or carbon emissions within one year. Studies of the UK EcoTeams demonstrated results after 5 months, the Dutch EcoTeams after 9 months, and the CRAGs and Green Streets after one year. Published sources do not provide data on the actual rate of change as studies of the programmes compared information from the start and end of the interventions with no intermediate results.

\subsubsection{Durability and Generality}

Two issues frequently present in discussions related to behaviour change are the permanence of changes resulting from interventions, and the likelihood of changes in a single behaviour leading to changes in other environmentally significant behaviours [4,6,7]. De Young [30] referred to these two dimensions as durability and generality, with generality also including the likelihood of individuals who experience the intervention encouraging others (who have not) to change their behaviour. In follow-up studies of 151 participants who had completed EcoTeams in the UK two to three years earlier, over $90 \%$ stated that they had not only maintained the lifestyle changes they had made, but were also doing more to reduce their environmental impact [26,31].

In the Netherlands a follow-up study of EcoTeams households six to nine months after completion of the programme showed further statistically significant increases in pro-environmental behaviour. Two years after completion those increases were maintained or improved upon [27]. Prior to participation in EcoTeams, Dutch participants were compared with a sample matched for pro-environmental behaviours from a representative household survey on environmental behaviour 
conducted annually in the Netherlands. Eight pro-environmental behaviours were assessed to identify whether any improvement in pro-environmental behaviour might be attributable to participation in the EcoTeams programme. During the first year there was a statistically significant increase in the pro-environmental behaviour of EcoTeams participants compared to that of the comparison group, although the pro-environmental behaviour of the comparison group also increased. Over the following two years, the rate of increase in pro-environmental behaviour of the EcoTeams participants continued to increase relative to that of the comparison group [27].

No follow-up information was available for CRAGs or for Green Streets, although Lockwood and Platt [25] reported anecdotal evidence that some people living in the participating streets who were not part of the Green Street team were motivated to reduce their energy use and carbon emissions. Also, at least one of the Green Street teams held community meetings to share their experience and advice with people who had not been involved in the intervention.

Overall, where information is available, it seems that the small-group interventions considered here promote lasting change. Additionally it appears that small-group interventions have the potential both to encourage further pro-environmental behaviour in participating individuals and to inspire these individuals to encourage others to adopt changes. Although there is limited comparative data to indicate how much of the change in behaviour is directly attributable to participation in the small group, data from Dutch EcoTeams suggest that participation in the group was related to an increase in pro-environmental behaviour for participants compared to a sample of the Dutch population matched for pro-environmental behaviour.

\subsubsection{Particularism}

The particularism dimension addresses the question of whether an intervention can be universally applied or whether it is appropriate only for a particular group of individuals [30]. A central difference between participants in these interventions and the general population is that it is likely that those who join these programmes are interested in learning about how to change their behaviour. In addition, participants in small-group interventions are usually environmentally aware and are already involved in some pro-environmental behaviours $[23,24,26,27]$. When participants in the Dutch EcoTeams were compared to a national representative sample, prior to participation in EcoTeams, they were found to behave in a more pro-environmental way than $80 \%$ of the Dutch population [27]. In the UK EcoTeams the majority of participants interviewed as part of a longitudinal study were also involved in pro-environmental behaviours prior to joining EcoTeams [26]. Participants in CRAGs had carbon emissions that were approximately $5 \%$ lower than the UK average at the start of the CRAG, possibly reflecting involvement with pro-environmental behaviour before joining a CRAG [24].

For the Green Street programme, participants were drawn from eight different cities, and from a variety of domestic building types (e.g., semi-detached, terrace) reflecting the proportions of different building types found nationally [25]. The average carbon footprint of participants at the beginning of the Green Streets programme was slightly higher than the UK average and interviews with a sample of participants indicated that there were a variety of attitudes to the environment and to energy use. Both these characteristics suggest that at least some of the Green Streets participants were not already involved in pro-environmental behaviour. Interviews suggest that at least part of the motivation for becoming involved was the money provided by British Gas for improvements and the prospect of winning a prize.

Evidence from the programmes considered here suggests that small-group interventions may be best suited to those with prior green intentions and those who are already engaged in pro-environmental behaviour. Additionally, although evidence from Green Street indicates that participants did not start with specifically pro-environmental attitudes, the high level of funding from British Gas introduced a strong financial incentive which is likely to have influenced participation, drawing in those who were financially motivated. Therefore these small-group programmes may not be applicable to the wider population. 


\section{Understanding the Effectiveness of Small-Group Interventions}

Our evaluation of the four small-group interventions suggests that they are unusually effective in promoting both substantial and durable changes in behaviour leading to measurable, objective reductions in energy use and carbon emissions. These interventions appear to act relatively quickly. Furthermore, the sustained increase in pro-environmental behaviour that occurs after the intervention ends suggests that they encourage the continued adoption of new pro-environmental behaviours. There is also some evidence that participants encourage others who did not take part in the programme to adopt pro-environmental behaviours. However, participants in small-group interventions are clearly not representative of the wider population. While we cannot assume that small-group interventions would be effective for those with less interest in pro-environmental behaviour, understanding the mechanisms underlying the success of the small-group programmes might be helpful in informing interventions that are more widely applicable. Previous researchers have proposed that the success of these small-group interventions is related to the supportive context provided by the group, a context which allows for re-examination of a wide range of behaviours $[22,23,25,27,35,36]$. They argue that this supportive context may be created by three elements: feedback, social support and engagement with information. Additional elements which have also been mentioned as potentially important include being part of a group whose social norms encourage pro-environmental behaviour and making a public commitment to change one's behaviour [22-27]. With the exception of an investigation of a single travel-related behaviour among Dutch EcoTeams participants, however, studies of small-group interventions have not explored in-depth the mechanisms which underlie these elements [27].

\section{The Reasonable Person Model}

One aim of this review is to explore whether the RPM might further our understanding of the processes underlying the success of these small-group interventions in facilitating reductions in energy use and carbon emissions over the long term. The RPM's emphasis on mental models, effectiveness and being needed appears to be reflected in observations that have been made previously in the literature about these small-group interventions [22-27]. The RPM may provide a coherent and integrative theoretical framework that encompasses the elements identified by previous researchers. Such a framework might then be helpful in designing and implementing other pro-environmental behaviour change programmes which might successfully promote substantial changes in behaviour across the wider population.

\subsection{Building and Extending Mental Models}

The first aspect of the RPM concerns the process of building and extending mental models. This relates to both the availability of information and the ability to explore and integrate that information with one's own knowledge. The small-group interventions provide opportunities both for gaining new information and for exploring existing knowledge with other people. In evaluations of UK EcoTeams $[22,26]$ and CRAGs $[23,24]$ the importance of the provision of information is highlighted and is anecdotally linked to the mechanisms of discussion or learning from others. Staats et al. [27] proposed that as well as providing practical 'how to' advice about possible behaviour changes, information can increase both an awareness of a problem and an awareness of what others are doing. Information can therefore provide not only procedural knowledge but can also increase the incentive to act by presenting new models of behaviour.

The opportunity to build and extend mental models might also reflect the move from habitual to reasoned behaviour which Staats et al. [27] suggested may be important to the success of the Dutch EcoTeams, with reasoned behaviour the result of re-examining and expanding mental models. The importance of the shift from practical to discursive consciousness proposed by Nye and Burgess [26] as an explanation for the success of UK EcoTeams might also reflect a more active engagement with mental models of pro-environmental behaviour. Hargreaves et al. [22] and Howell [23] both emphasised the 
importance of information which allows people to build on existing knowledge and behaviour in promoting increases in pro-environmental behaviour. The importance of mental models is summarised by the conclusion in Nye and Burgess [26] that EcoTeams "encourage a process of 'joined up thinking' about the environmental impacts of a lifestyle and the routines within it" [26] (p. 84).

\subsection{Develop and Exercise Competence}

The second aspect of the RPM concerns the potential to develop and exercise competence and it is achieved by small-group interventions through information provision and through feedback. Feedback is identified as an important element of the programmes and a mechanism which supports change according to Staats et al. [27] and Hargreaves et al. [22]. These authors argue that feedback might be an effective mechanism because it increases feelings of self-efficacy as participants are able to see that the changes they make to their behaviour do make a difference to the environmental impact of their lives. Nye and Burgess [26] suggested that feedback may increase feelings of control and competence, while Hargreaves et al. [22] suggested that feedback may provide intrinsic satisfaction, due to increased feelings of self-efficacy and competence [3]. Hargreaves et al [22] further proposed that these feelings might result from the ability of feedback to demonstrate the link between changes in behaviour and reductions in waste, water, and energy use thereby promoting feelings of competence.

\subsection{Participate and Feel Needed}

The third aspect of the RPM concerns the importance of participation and feeling needed. Participation in group meetings has been identified as important both for social support and for diffusion of information. Hargreaves et al. [22] and Staats et al. [27] suggested that supportive social interaction was crucial to the effectiveness of both the EcoTeams programme in the UK and in the Netherlands. Staats et al. [27] also speculated that such social interaction may be important because of its effect on personal and social norms. Howell $[23,24]$ suggested that regular meetings provided the opportunities for the moral support and information sharing identified by participants in CRAGs as important to their success in reducing energy use and carbon emissions. Quotes included in her report suggest that this "moral support" is the result of feeling part of something bigger and of being respected for what you are doing [23]. These observations in the literature reflect the RPM's notion of an environment being supportive of one's desire to participate, contribute and be needed.

\section{Discussion}

We undertook a review of small-group techniques to explore their ability to promote substantial shifts in behaviour towards reduced energy use and sustainable, low carbon lifestyles. Four examples were identified which contained both objective data on energy use (e.g., energy data from gas and electricity meters) and descriptive insight into the programme format.

The evidence from these four cases demonstrates that small-group interventions promote substantial and durable reductions in energy use and increases in pro-environmental behaviour on the scale needed to contribute to meeting carbon reduction targets in developed countries. Analysis using a set of dimensions for understanding the effectiveness of behaviour change interventions showed that these interventions are effective for the four dimensions of speed, reliability, durability and generality [30]. For the particularism dimension, however, the findings suggest that small-group interventions may only be suited to particular types of individuals, specifically, those with existing pro-environmental beliefs, those who are already engaged in pro-environmental behaviour, or those who have been motivated by a financial incentive.

Due to the intensive and expensive nature of small-group interventions, however, and the likelihood that they will appeal primarily to a small cohort of already committed individuals, they are unlikely to generate change at the needed societal scale. Therefore we attempted to identify elements of these small-groups that could be applied to different intervention types to reach a wider section of the population. The review of small-group interventions presented here suggests that the 
social and cognitive environment provided by the small-group interventions, with an emphasis on sharing information and group support, is important to their success. The RPM provides a theoretical framework which encompasses those elements and therefore might be helpful in understanding how to take the lessons learned from small-group interventions and apply them in larger scale interventions.

Bamberg [37] has questioned the usefulness of the most commonly used theoretical frameworks for developing interventions, arguing that these theories are not useful for spanning the gap between intention and behaviour. The RPM specifically addresses the issue of how to influence behaviour by proposing that there are elements in the environment which will facilitate reasonable behaviour. Kaplan and Kaplan [20] suggested that an environment which provides an opportunity to build and extend mental models, to exercise and develop competence, and to participate and feel needed will promote reasonable behaviour. Findings from this review suggest that small-group interventions may provide such supportive informational environments where participants can examine, modify, and extend their mental models of how to live lower-carbon lives. Previous researchers have also suggested that small-group interventions may support feelings of effectiveness through increased self-efficacy and feelings of competence. Finally the importance attributed to social support by previous researchers may be related to the need to participate and feel needed.

The RPM appears to encompass suggestions from previous studies that the processes underlying the effectiveness of small-group interventions include increasing knowledge, increasing self-efficacy beliefs, and increasing competence $[22,24,26,27]$. It has been well documented that provision of information alone is not very effective in changing behaviour with evidence suggesting that increasing knowledge does not lead to behaviour changes [38]. As Frick et al. [39] noted, however, knowledge is necessary for successful action, particularly knowledge related to specific behaviours and to the effectiveness of different actions in achieving the desired goal. Discussion and the sharing of information were highlighted by previous researchers as central to how information was provided and understood by small-group participants.

The importance of discussion in the small groups seemed to have two elements: one was the diffusion of information, particularly local information [26] and the other was related to actively engaging with the information to understand how it could be applied to individual circumstances. Wilson and Irvine [40], in an evaluation of a variety of communication campaigns targeting pro-environmental behaviour, also concluded that the opportunity for discussion and exploration of issues with others contributed to increased behaviour change compared to interventions which provided information alone, without that opportunity for exploration. The provision of information in small-group interventions seems to be particularly important in facilitating effective action and this may be the result of the opportunity provided by the group for people to build and extend mental models of pro-environmental behaviour.

Our review suggests that presenting information in a way that helps people to reflect on their current behaviour and which allows them to re-engage repeatedly with that information may help them build better mental models of pro-environmental behaviour and increase their willingness to perform such behaviour. This raises important questions about how one might facilitate such model building in interventions that are implemented at a larger scale than small-group interventions. A recent study examining the results of the Energy Demand Research Project (EDRP) in the UK provides some insight into how this particular element identified in small-group interventions might be incorporated into a behaviour change initiative that has broader reach. The EDRP study compared the results of various interventions in a large scale consumer study run by a number of energy supply companies [41]. Each company designed their own intervention-many of which included provision of information; this variability allowed the effects of different types of information provision to be compared. After installing smart meters and providing initial instructions and guidance, one energy company supplied simple energy efficiency advice at intervals over the course of a year. Another energy company provided more comprehensive advice but only once at the start of the trial at the same time as the installation of a smart meter. Participants who received simpler advice regularly 
reduced their energy use more than those who received more comprehensive advice only once. The chance to repeatedly engage with information on energy efficiency may be related to the reductions in energy usage not seen in the participants who were presented with information only once.

There are clearly opportunities for future research both in relation to understanding mechanisms that might underlie the effectiveness of small-group interventions and the scalability of such elements to other intervention types. For example, while studies of both the Dutch and UK EcoTeams argue that self-efficacy is linked to the success of the small-group interventions neither study attempts to measure self-efficacy. Thus research could fruitfully examine the ways in which the environment provided by these interventions may facilitate feelings of self-efficacy and opportunities to develop and exercise competence. Similarly, the socially supportive environment of the group meeting format has been noted as crucial to the success of all the interventions reviewed here. This may be related to the opportunity to participate and feel needed; it may also reflect the importance of interaction with a group whose social norms support pro-environmental behaviour. Future research might usefully examine ways of providing a socially supportive environment comparable to that found in small-group interventions. For example, there has been some research on the effectiveness of social media in offering supportive networks for reducing carbon emissions [42]. An additional line of investigation related to understanding small-group interventions themselves is to consider alternative study designs, ones that, for example, include comparison groups. This would not only facilitate an understanding of the durability and generality of behaviour change associated with small-group interventions but also provide further insight into their appeal. Lastly, there are opportunities to further examine the applicability and usefulness of the RPM as a framework for the design and evaluation of interventions.

\section{Conclusions}

The small-group interventions examined here appear to be successful in promoting changes in pro-environmental behaviour leading to substantial and durable reductions in household energy use and carbon emissions. The need for a step change in bringing about the much needed transition to a low carbon society is urgent. Here we sought to demonstrate that small-group interventions are reliable at promoting significant and durable behaviour change across multiple behavioural domains including energy use. The results of our review suggest that there are large potential reductions in carbon emissions that could be realised over the short term through the use of small-group interventions within the most motivated segment of the population. In addition, there may be valuable lessons to be learned from the effectiveness of these small-group interventions that could be applied more widely.

This review also suggests that considering human informational needs when designing interventions may be effective in promoting meaningful and lasting changes in behaviour. Presenting information in a way that helps people to reflect on their current behaviour and to re-engage repeatedly with the information may help them build better mental models of pro-environmental behaviours and increase their willingness to perform such behaviours. The small-group format of the programmes discussed here appears to be effective in supporting individuals in this way. The supportive informational environment provided by the small-group interventions may also allow people to overcome perceived barriers to pro-environmental behaviour thereby building opportunities to develop competence and facilitating involvement. The RPM may thus provide useful insight for the development of successful pro-environmental behaviour change programmes.

Acknowledgments: This paper was developed from a research project funded by De Montfort University. Katherine Irvine's contribution to manuscript development was supported by the Scottish Government's Rural and Environment Science and Analytical Services Division (RESAS). Richard Bull and Andrew Reeves commented on an earlier version of this paper. The authors would also like to thank the anonymous reviewers for their comments.

Author Contributions: Jill Fisher undertook the review; Katherine Irvine contributed to refinement of the critique of interventions; both authors contributed to the development of the manuscript.

Conflicts of Interest: The authors declare no conflict of interest. 


\section{References}

1. Spence, A.; Pigeon, N. Psychology, climate change and sustainable. Environment 2009, 51, 8-18. [CrossRef]

2. Dietz, T.; Gardner, G.T.; Gilligan, J.; Stern, P.C.; Vandenbergh, M.P. Household actions can provide a behavioral wedge to rapidly reduce U.S. carbon emissions. Proc. Natl. Acad. Sci. USA 2009, 106, 18452-18456. [CrossRef] [PubMed]

3. De Young, R. New ways to promote proenvironmental behavior: Expanding and evaluating motives for environmentally responsible behavior. J. Soc. Issues 2000, 56, 509-526. [CrossRef]

4. Haq, G.; Whiteleg, J.; Cinderby, S.; Owen, A. The use of personalised social marketing to foster voluntary behavioural change for sustainable travel and lifestyles. Local Environ. 2008, 13, 549-569. [CrossRef]

5. Jackson, T. Motivating Sustainable Consumption; A report to the Sustainable Development Research Network; University of Surrey: Surrey, UK, 2005.

6. Abrahamse, W.; Steg, L.; Vlek, C.; Rothengatter, T. A review of intervention studies aimed at household energy conservation. J. Environ. Psychol. 2005, 25, 273-291. [CrossRef]

7. Thøgersen, J.; Ölander, F. Spillover of environment-friendly consumer behaviour. J. Environ. Psychol. 2003, 23, 225-236. [CrossRef]

8. McKenzie-Mohr, D. Fostering sustainable behavior through community-Based social marketing. Am. Psychol. 2000, 55, 531-537. [PubMed]

9. Steg, L.; Vlek, C. Encouraging pro-environmental behaviour: An integrative review and research agenda. J. Environ. Psychol. 2009, 29, 309-317.

10. Barr, S.; Gilg, A.W.; Ford, N. The household energy gap: Examining the divide between habitual- and purchase-related conservation behaviours. Energy Policy 2005, 33, 1425-1444. [CrossRef]

11. Kaiser, F.G.; Byrka, K.; Hartig, T. Reviving Campbell's paradigm for attitude research. Personal. Soc. Psychol. Rev. 2010, 14, 351-367.

12. Bratt, C.; Stern, P.C.; Matthies, E.; Nenseth, V. Home, car use, and vacation: The structure of environmentally significant individual behavior. Environ. Behav. 2015, 47, 436-473. [CrossRef]

13. Stern, P.C. Toward a coherent theory of environmentally significant behavior. J. Soc. Issues 2000, 56, 407-424.

14. Whitmarsh, L. Behavioural responses to climate change: Asymmetry of intentions and impacts. J. Environ. Psychol. 2009, 29, 13-23. [CrossRef]

15. Kaklamanou, D.; Jones, C.R.; Webb, T.L.; Walker, S.R. “Using public transport can make up for flying abroad on holiday": Compensatory green beliefs and energy-related behavior. Environ. Behav. 2015, 47, 184-204. [CrossRef]

16. Botetzagias, I.; Malesio, C.; Poulou, D. Electricity curtailment behaviors in Greek households: Different behaviors, different predictors. Energy Policy 2014, 69, 415-424. [CrossRef]

17. Karlin, B.; Davis, N.; Sanguinetti, A.; Gamble, K.; Kirkby, D.; Stokols, D. Dimensions of Conservation Exploring Differences Among Energy Behaviors. Environ. Behav. 2014, 46, 423-452. [CrossRef]

18. Ajzen, I. The theory of planned behavior. Organ. Behav. Hum. Decis. Process. 1991, 50, 179-211. [CrossRef]

19. Kaplan, R.; Kaplan, S. Bringing out the best in people: A psychological perspective. Conserv. Bio. 2008, 22, 826-829.

20. Kaplan, S.; Kaplan, R. Creating a larger role for environmental psychology: The reasonable person model as an integrative framework. J. Environ. Psychol. 2009, 29, 329-339. [CrossRef]

21. Fisher, J.; Irvine, K. Reducing household energy use and carbon emissions: The potential for promoting significant and durable changes through group participation. In Proceedings of the IESD PhD Conference: Energy and Sustainable Development, Leicester, UK, 21 May 2010; pp. 49-57.

22. Hargreaves, T.; Nye, M.; Burgess, J. Social experiments in sustainable consumption: An evidence-based approach with potential for engaging low-income communities. Local Environ. 2008, 13, 743-758. [CrossRef]

23. Howell, R. The Experience of Carbon Rationing Action Groups: Implications for a Personal Carbon Allowances Policy; UK Energy Research Centre: Oxford, UK, 2009.

24. Howell, R.A. Living with a carbon allowance: The experiences of carbon rationing action groups and implications for policy. Energy Policy 2012, 41, 250-258. [CrossRef]

25. Lockwood, M.; Platt, R. Green Streets: Final Report to British Gas; Institute for Public Policy Research: London, UK, 2009. 
26. Nye, M.; Burgess, J. Promoting Durable Change in Household Waste and Energy use Behavior; University of East Anglia: Norwich, UK, 2008.

27. Staats, H.; Harland, P.; Wilke, H.A.M. Effecting durable change: A team approach to improve environmental behavior in the household. Environ. Behav. 2004, 36, 341-367. [CrossRef]

28. Jansson, W.; Almberg, B.; Grafstrom, M.; Winblad, B. The circle model—Support for relatives of people with dementia. Int. J. Geriatr. Psychiatry 1998, 13, 674-681. [CrossRef]

29. Landtblom, A.; Lang, C.; Flensner, G. The study circle as a tool in multiple sclerosis patient education in Sweden. Patient Prefer. Adher. 2008, 2, 225-232. [CrossRef]

30. De Young, R. Changing behavior and making it stick. Environ. Behav. 1993, 25, 485-505. [CrossRef]

31. EcoTeams Evaluation Report; Global Action Plan: London, UK, 2008.

32. Staats, H.; Harland, P. The Ecoteam Program in the Netherlands, Study 4: A longitudinal Study on the Effects of the EcoTeam Program on Environmental Behavior and Its Psychological Backgrounds; Centre for Environmental and Energy Research: Leiden, The Netherlands, 1995.

33. Changing Environmental Behaviour: A Review of the Evidence from Global Action Plan; Global Action Plan: London, UK, 2006.

34. Seyfang, G.; Lorenzoni, I.; Nye, M. Personal Carbon Trading: notional Concept or Workable Proposition? Exploring Theoretical, Ideological and Practical Underpinnings; CSERGE Working Paper, EDM 07-03; University of East Anglia: Norwich, UK, 2003.

35. Hielscher, S. Carbon Rationing Action Groups: An Innovation History; University of Sussex: Brighton, UK, 2013.

36. Burgess, J. Sustainable consumption: Is it really achievable? Consum. Policy Rev. 2003, 13, 78-84.

37. Bamberg, S. Changing environmentally harmful behaviors: A stage model of self-regulated behavioral change. J. Environ. Psychol. 2013, 34, 151-159. [CrossRef]

38. Schultz, P. Conservation means behavior. Conserv. Bio. 2011, 25, 1080-1083. [CrossRef] [PubMed]

39. Frick, J.; Kaiser, F.G.; Wilson, M. Environmental knowledge and conservation behavior: Exploring prevalence and structure in a representative sample. Personal. Individ. Differ. 2004, 3, 1597-1613. [CrossRef]

40. Wilson, C.; Irvine, K.N. Bottom-up communication: Identifying opportunities and limitations through an exploratory field-based evaluation. Energy Effic. 2013, 6, 91-104. [CrossRef]

41. Energy Demand Research Project: Final Analysis; AECOM: Hertfordshire, UK, 2011.

42. Foster, D.; Lawson, S. 'Liking' persuasion: Case Studies in Social Media for Behavior Change. In Proceedings of the CHI 13, Paris, France, 27 April-5 May 2013.

(C) 2016 by the authors; licensee MDPI, Basel, Switzerland. This article is an open access article distributed under the terms and conditions of the Creative Commons by Attribution (CC-BY) license (http:/ / creativecommons.org/licenses/by/4.0/). 